\title{
Cognitive Profile of Amyloid Burden and White Matter Hyperintensities in Cognitively Normal Older Adults
}

\author{
Trey Hedden, ${ }^{1,5}$ Elizabeth C. Mormino, ${ }^{2}$ Rebecca E. Amariglio, ${ }^{2,6}$ Alayna P. Younger, ${ }^{1,3}$ Aaron P. Schultz, ${ }^{1,2,3}$ \\ J. Alex Becker, ${ }^{4}$ Randy L. Buckner, ${ }^{1,3,5,7,8}$ Keith A. Johnson, ${ }^{2,4,5,6}$ Reisa A. Sperling, ${ }^{1,2,6}$ and Dorene M. Rentz ${ }^{2,6}$ \\ ${ }^{1}$ Athinoula A. Martinos Center for Biomedical Imaging, Department of Radiology, Massachusetts General Hospital, Charlestown, Massachusetts 02129; \\ ${ }^{2}$ Department of Neurology, ${ }^{3}$ Department of Psychiatry, ${ }^{4}$ Division of Nuclear Medicine and Molecular Imaging, and ${ }^{5}$ Department of Radiology, Massachusetts \\ General Hospital, Harvard Medical School, Boston, Massachusetts 02114; ${ }^{6}$ Center for Alzheimer Research and Treatment, Department of Neurology, Brigham and \\ Women's Hospital, Harvard Medical School, Boston, Massachusetts 02115; 7 Department of Psychology and Center for Brain Science, Harvard University, \\ Cambridge, Massachusetts 02138; and ${ }^{8}$ Howard Hughes Medical Institute at Harvard University, Cambridge, Massachusetts 02115
}

Amyloid burden and white matter hyperintensities (WMH) are two common markers of neurodegeneration present in advanced aging. Each represents a potential early indicator of an age-related neurological disorder that impacts cognition. The presence of amyloid is observed in a substantial subset of cognitively normal older adults, but the literature remains equivocal regarding whether amyloid in nondemented populations is deleterious to cognition. Similarly, WMH are detected in many nondemented older adults and there is a body of evidence indicating that $\mathrm{WMH}$ are associated with decreased executive function and other cognitive domains. The current study investigated amyloid burden and WMH in clinically normal older adult humans aged 65-86 $(N=168)$ and examined each biomarker's relation with cognitive domains of episodic memory, executive function, and speed of processing. Factors for each domain were derived from a neuropsychological battery on a theoretical basis without reference to the relation between cognition and the biomarkers. Amyloid burden and WMH were not correlated with one another. Age was associated with lower performance in all cognitive domains, while higher estimated verbal intelligence was associated with higher performance in all domains. Hypothesis-driven tests revealed that amyloid burden and WMH had distinct cognitive profiles, with amyloid burden having a specific influence on episodic memory and WMH primarily associated with executive function but having broad (but lesser) effects on the other domains. These findings suggest that even before clinical impairment, amyloid burden and WMH likely represent neuropathological cascades with distinct etiologies and dissociable influences on cognition.

\section{Introduction}

A subset of clinically normal older adults exhibit neuropathological changes associated with disorders such as Alzheimer's disease

Received May 18, 2012; revised Sept. 10, 2012; accepted Sept. 17, 2012.

Author contributions: T.H., R.E.A., R.L.B., K.A.J., R.A.S., and D.M.R. designed research; T.H., R.E.A., A.P.Y., J.A.B., and D.M.R. performed research; T.H., E.C.M., A.P.Y., A.P.S., and J.A.B. analyzed data; T.H., E.C.M., R.L.B., K.A.J., R.A.S., and D.M.R. wrote the paper.

This research was performed in part at the Athinoula A. Martinos Center for Biomedical Imaging at the Massachusetts General Hospital, using resources provided by the Center for Functional Neuroimaging Technologies, P41RR14075, a P41 Regional Resource supported by the Biomedical Technology Program of the National Center for Research Resources (NCRR)-National Institutes of Health. This work also involved the use of instrumentation supported by the NCRR Shared Instrumentation Grant Program and/or High-End Instrumentation Grant Program; specifically, grant numbers 1S10RRO23401, 1S10RR019307, and 1S10RR023043. Funding was provided by National Institute on Aging Grants P01 AG036694, P50 AG0513421, R01 AG034556, R01 AG027435, P41 RR14075, and K01 AG040197; The Alzheimer's Association Grant IIRG-08-90934; and by the Howard Hughes Medical Institute. We thank Lauren Wadsworth, Natacha Lorius, and Emily Shire for assistance during subject recruitment and data collection. The Massachusetts Alzheimer's Disease Research Center, Gad Marshall, Brendon Boot, and Mykol Larvie provided assistance with clinical and neuropsychological characterization of participants. The Massachusetts General Hospital Molecular Imaging PET Core provided assistance with amyloid imaging. Christopher Gidicsin, Jacqueline Maye, Bill Klunk, and Chet Mathis provided assistance with PiB imaging. Minjie Wu provided software for labeling WMH and Koene Van Dijk advised on the adaptation of this software. Donald McLaren provided valuable discussion. Dr. Herman Buschke and the Albert Einstein College of Medicine of Yeshiva University provided the Memory Capacity Test.

The authors declare no competing financial interests.

Correspondence should be addressed to Trey Hedden, Athinoula A. Martinos Center for Biomedical Imaging, 149 13th Street, Suite 2301, Charlestown, MA 02129. E-mail: hedden@nmr.mgh.harvard.edu.

DOI:10.1523/JNEUROSCI.2462-12.2012

Copyright $\odot 2012$ the authors $\quad 0270-6474 / 12 / 3216233-10 \$ 15.00 / 0$
(AD) and cerebrovascular disease (CVD). Approximately $30 \%$ of such individuals over the age of 60 have elevated amyloid burden, an indication of the amyloid plaques that are a hallmark of AD (Rabinovici and Jagust, 2009; Klunk, 2011; Sojkova and Resnick, 2011). Elevated levels of white matter hyperintensities (WMH) associated with CVD are prevalent among clinically normal older adults (Ylikoski et al., 1995). Amyloid accumulation and white matter abnormalities are two of the most commonly observed biomarkers of pathology among clinically normal older adults and represent chronically progressive neuropathologies with potential clinical implications. Some investigators have hypothesized a mechanistic relationship between amyloid and $\mathrm{WMH}$, possibly operating through vascular amyloid deposition observed as microbleeds as in cerebral amyloid angiopathy (CAA) with apolipoprotein $\varepsilon 4$ as a common genetic predisposition (Brun and Englund, 1986; Chen et al., 2006; Holland et al., 2008; Brickman et al., 2009; Hommet et al., 2011; Horsburgh et al., 2011; Grimmer et al., 2012). Although associations between amyloid and white matter neuropathology have been observed in CAA and late-stage $\mathrm{AD}$, emerging evidence suggests that the presence of amyloid burden and WMH are not always correlated and may represent distinct neuropathological cascades among cognitively normal older adults (Rutten-Jacobs et al., 2011; Hedden et al., 2012; Marchant et al., 2012). Here, we examine whether bio- 
markers of amyloid and WMH are related to distinct cognitive domains.

We have previously hypothesized that advanced aging is associated with multiple neuropathological cascades, which may differentially impact cognitive domains (Buckner, 2004; Hedden and Gabrieli, 2004). Amyloid burden may primarily impact memory systems, whereas white matter degradation during aging may differentially impact executive control systems (Hedden et al., 2012). The literature on relationships between in vivo amyloid burden and cognition is large and varied, although studies with larger sample sizes or longitudinal methods tend to demonstrate a stronger association of amyloid burden with memory than with other cognitive domains (Roe et al., 2008; Resnick et al., 2010; Klunk, 2011; Pike et al., 2011; Jack et al., 2012; Oh et al., 2012; Rodrigue et al., 2012; Storandt et al., 2012). In contrast, the relationship between white matter degradation and cognition may be less specific, but executive control may be somewhat more affected than other cognitive domains (Gunning-Dixon and Raz, 2000; Oosterman et al., 2004).

Recent advances in imaging allow detection of amyloid burden and WMH in cognitively normal individuals, providing an opportunity to discover the correspondence of each to separable cognitive domains. One purpose of this endeavor is to better recognize each pathology as signified by a specific profile of cognition, insofar as domain specificity can be identified. We hypothesized that amyloid burden would have a cognitive profile preferentially related to memory, whereas WMH would have a cognitive profile preferentially related to executive function. To test these hypotheses, we examined cognitively normal older individuals assessed with an extensive neuropsychological battery and imaging measures of amyloid burden and WMH.

\section{Materials and Methods}

Sample characteristics. We conducted neuropsychological testing on 168 (95 female) cognitively normal, community-dwelling older adults (aged $65-86, M=73.24, \mathrm{SD}=5.80$ ). These individuals are participants in the Harvard Aging Brain Study, an ongoing longitudinal study currently in the baseline assessment phase. Participants were generally well educated (years of education: $M=16.02, \mathrm{SD}=3.03$ ) with high estimated verbal intelligence (VIQ; $M=121.9, \mathrm{SD}=8.4$ estimated from the American National Adult Reading Test, Ryan and Paolo, 1992) and high socioeconomic status (SES) as measured by the Hollingshead (1957) scale $(M=$ $28.37, \mathrm{SD}=15.51$; the scale ranges from 11 to 77 with lower scores indicating higher SES). A comparison sample of 38 younger adults (aged $19-32, M=22.03, \mathrm{SD}=3.69$; years of education: $M=14.58, \mathrm{SD}=1.72$; estimated VIQ: $M=118.3, \mathrm{SD}=5.2$ ) completed the same neuropsychological testing as the older adults. All participants had a Clinical Dementia Rating of 0 (Morris, 1993), performed no worse than 1.5 SD units below the age- and education-corrected norm on the Logical Memory IIa subtest of the Wechsler Memory Scale-Revised (Wechsler, 1987), and scored 26 or above on the Mini-Mental State Examination (Folstein et al., 1975). Participants were excluded if previously diagnosed with a neurological or psychiatric condition or if they scored $>11$ on the Geriatric Depression Scale (Yesavage et al., 1982). All participants had normal or corrected to normal vision. Participants provided informed consent in accordance with protocols approved by the Partners Healthcare Inc. Institutional Review Board. Fifteen of the 168 subjects (9\%) were excluded from at least one imaging visit because of contraindications uncovered after initial enrollment. Because of the staged nature of the visits (all baseline visits must be completed within 6 months), positron emission tomography (PET) amyloid imaging and magnetic resonance imaging (MRI) estimates of WMH were currently available for 109 of the older adults. Data from 20 (18\%) of these participants were included in previous analyses of relationships between amyloid or WMH and cognition (Hedden et al., 2009, 2012; Rentz et al., 2010, 2011).
Neuropsychological tasks. Participants completed an extensive battery of neuropsychological and behavioral tasks selected primarily to represent executive function component processes, episodic memory, and processing speed. The variables selected from each task were chosen through discussion with neuropsychologists and on the basis of prior literature without reference to the correlation matrix or other data from the current sample. Executive function was made up of the component processes of fluency, working memory, and switching. The selected measures for fluency were the sum of the words produced in $60 \mathrm{~s}$ for the letters F, A, and S (Benton et al., 1983) and the sum of the words produced in $60 \mathrm{~s}$ for each of the categories animals, vegetables, and fruits (Monsch et al., 1992). For working memory they were the number of trials correctly completed for the Letter-Number Sequencing subtest of the Wechsler Adult Intelligence Scale-III (Wechsler, 1997), the highest level completed for the Digit Span Backward subtest of the WAIS revised (WAIS-R; Wechsler, 1981), and the number of errors produced on the Self-Ordered Pointing (SOP) task (adapted from Petrides and Milner, 1982 and Shimamura and Jurica, 1994). Selected measures for switching were the across-block switching reaction time (RT) effect (a difference score of RTs during switch vs nonswitch blocks) from the Number-Letter (NL) task (adapted from Rogers and Monsell, 1995 and Miyake et al., 2000), the compatibility RT effect (a difference score of RTs during incompatible vs compatible trials) from a modified Flanker task (adapted from Eriksen and Eriksen, 1974 and Ridderinkhof et al., 1999 to include a compatibility manipulation in which participants must switch between responding with the same or opposite direction as the central arrow as cued by a color cue), and the Trail Making Test (TMT) time to complete Form B minus Form A (Reitan, 1979). For episodic memory, they included the cued recall names and cued recall occupations scores from the Face-Name Associative Memory Exam (Rentz et al., 2011; Amariglio et al., 2012), the delayed recall score from the Six-Trial Selective Reminding Test (Masur et al., 1990), and List 2 free recall from the Memory Capacity Test (H. Buschke, personal communication; Rentz et al., 2010). Processing speed selected measures were the median RT from the nonswitching blocks from the NL task, the TMT time to complete Form A, and the number of items completed on the digit-symbol subtest of the WAIS-R (Wechsler, 1981).

Confirmatory factor analysis. Confirmatory factor analysis was conducted using AMOS 18.0 (Amos Development). Missing data were imputed with mean replacement. Only 6 of the 15 observed variables had missing data and a maximum of $6.5 \%$ of values were missing for any task. To reduce the reliance on individual subtests, which are necessarily influenced by measurement error, and to examine the shared variance between tasks, we used confirmatory factor analysis to model a hypothesized factor structure. We hypothesized that the cognitive variables under investigation would be organized into three primary factors: executive function, episodic memory, and processing speed. We further hypothesized that executive function would be represented by a secondorder factor consisting of the variance shared by three first-order factors: fluency, working memory, and switching. This factor structure was hypothesized based on prior work indicating that executive function has multiple component processes and is distinct from episodic memory and processing speed (Miyake et al., 2000; Park et al., 2002; Salthouse et al., 2003, 2011Friedman and Miyake, 2004; Hedden and Yoon, 2006). The hypothesized model is depicted in Figure 1. Briefly, we hypothesized that each observed variable would be explained by a single factor, and that all correlations involving fluency, working memory, and switching would operate through their shared variance in the executive function secondorder factor. We also allowed for correlated errors between observed variables drawn from the same task.

Before examining relationships of amyloid burden and WMH to the cognitive factors, we evaluated and finalized the factor structure on the neuropsychological data without links to the imaging data. We then conducted a path analysis by simultaneously entering age, estimated VIQ, amyloid burden, and WMH as predictors of the cognitive factors. We hypothesized that age would be negatively related to all factors, VIQ would be positively related to all factors, that amyloid would be negatively related to episodic memory, and that WMH would be negatively related to executive function. Because of the strong directional nature of 
our hypotheses, we used one-tailed significance values when evaluating individual correlations and loadings in the path analyses. The number of tests relevant to each hypothesis was limited by the number of factors (three for comparisons between executive function, memory, and speed; three for the component factors of fluency, working memory, and switching).

The primary measure of model fit used was the $\chi^{2}$ statistic, which should be nonsignificant for a well fitting model. Relative change in $\chi^{2}$ was used when comparing alternative models. We also report two common fit indices: the Tucker-Lewis Index (TLI), for which values $>0.95$ indicate good fit, and the root mean square of approximation (RMSEA), which should be $<0.05$ and accompanied by a nonsignificant $p$ value for closeness of fit (PCLOSE) (Hu and Bentler, 1999).

Amyloid imaging acquisition and analysis. Amyloid burden was measured with $N$-methyl-[ $\left.{ }^{11} \mathrm{C}\right]$-2-(4-methylaminophenyl)-6-hydroxybenzothiazole (Pittsburgh Compound B; PiB), which binds to fibrillar amyloid, and was prepared at Massachusetts General Hospital as described previously (Mathis et al., 2003; Klunk et al., 2004). Participants underwent PiB PET imaging as described previously (Gomperts et al., 2008; Hedden et al., 2009, 2012; Sperling et al., 2009). Briefly, data were acquired using a Siemens/CTI ECAT HR + scanner (3D mode; 63 image planes; $15.2 \mathrm{~cm}$ axial field of view; $5.6 \mathrm{~mm}$ transaxial resolution and $2.4 \mathrm{~mm}$ slice interval; 39 frames: $8 \times 15 \mathrm{~s}, 4 \times 60 \mathrm{~s}, 27 \times 120 \mathrm{~s}$ ). After a transmission scan, 8.5 to $15 \mathrm{mCi}$ $\left[{ }^{11} \mathrm{C}\right]-\mathrm{PiB}$ was injected as a bolus and followed immediately by a $60 \mathrm{~min}$ dynamic acquisition. PET data were reconstructed and attenuation corrected, and each frame was evaluated to verify adequate count statistics and absence of head motion (interframe head motion, if present, was corrected before further processing).

The dynamic PET data were reconstructed with scatter correction using commercially available routines for 3D PET data. The average of the initial $0-8 \mathrm{~min}$ of dynamic PET data was spatially normalized to a PET MNI template using SPM8. PET data were parameterized by the distribution volume ratio (DVR) computed using the Logan graphical analysis technique (Logan et al., 1990) applied to the frame data acquired 40-60 min after injection; this method has been fully validated for PiB imaging (Price et al., 2005). Time-activity curves were measured in each brain region under analysis (region of interest or voxel) and in a reference region in cerebellar cortex known to contain low levels of fibrillar amyloid. This approach has been applied to numerous PiB studies (Lopresti et al., 2005; Price et al., 2005;Fagan et al., 2006; Johnson et al., 2007) and yields data that are similar to arterial blood input methods (Lopresti et al., 2005).

For each subject an index of PiB binding in cortical regions was calculated using the dynamic data via Logan graphical modeling within a large aggregate cortical region of interest consisting of frontal, lateral parietal and temporal, and retrosplenial cortices (the FLR region). PiB retention in the FLR region is substantial in patients with diagnosed $\mathrm{AD}$ and has been used as a summary measure of $\mathrm{PiB}$ retention in previous studies (Johnson et al., 2007; Gomperts et al., 2008; Hedden et al., 2009, 2012). FLR DVR was log-transformed because of the non-normal distribution of $\mathrm{PiB}$ values and treated as a continuous variable in all analyses. Despite this transformation, non-normality of the distribution remains evident and individuals with very high values of $\mathrm{PiB}$ may have a disproportionate influence on the results.

MRI data acquisition. Participants underwent MRI on a Siemens TrioTIM 3 T scanner equipped with a 12-channel phased-array whole-head coil. Head motion was restrained with a foam pillow and extendable padded head clamps. Earplugs were used to attenuate scanner noise. High-resolution 3D T1-weighted multi-echo magnetization-prepared, rapid acquisition gradient echo anatomical images were collected with the following parameters: $\mathrm{TR}=2200 \mathrm{~ms}$; multi-echo TEs $=1.54 \mathrm{~ms}, 3.36$ $\mathrm{ms}, 5.18 \mathrm{~ms}$, and $7 \mathrm{~ms}$; FA $=7^{\circ}, 4 \times$ acceleration, $1.2 \times 1.2 \times 1.2 \mathrm{~mm}$ voxels. Fluid attenuation inversion recovery (FLAIR) images for visualization of white matter lesions were collected with the following parameters: $\mathrm{TR}=6000 \mathrm{~ms}, \mathrm{TE}=454 \mathrm{~ms}, \mathrm{TI}=2100 \mathrm{~ms}, 1 \times 1 \times 1.5 \mathrm{~mm}$ voxels.

WMH analyses. WMH were identified from each individual's FLAIR image with an automated fuzzy-connected algorithm previously validated against a visual grading system (Wu et al., 2006) and using methods described previously (Hedden et al., 2012). This automated WMH seg- mentation method involves (1) automatic identification of WMH seeds based on the intensity histogram of the FLAIR image, (2) using a fuzzyconnected algorithm to segment the WMH clusters, (3) iteratively updating the set of seeds, and (4) combining the WMH clusters into a final WMH segmentation. The histogram of the skull-stripped (Smith, 2002) FLAIR image was used to define a threshold, which was set to be the mean \pm 2.5 SDs. From the resulting WMH segmentation we extracted the total WMH volume in $\mathrm{mm}^{3}$ within a mask defined by the Johns Hopkins University White Matter Atlas (Wakana et al., 2004), which was reverse normalized to the native space of each individual's FLAIR image. Because the automated algorithm is designed to detect regions of relative hyperintensity, this can lead to false detections, particularly in individuals with little or no areas of true hyperintensity (as in younger adults). Assumptions built into the algorithm, such as the threshold applied and the regions included in the mask, may introduce systematic bias; however, the classification and ordering of individuals by the resulting $\mathrm{WMH}$ estimates appear to be robust to changes in these assumptions. WMH volumes were log-transformed because of the non-normal distribution of WMH values and treated as a continuous variable in all analyses.

\section{Results}

\section{Confirmatory factor analysis and extraction of factor scores}

In confirmatory factor analysis, multiple individual task variables are used to estimate latent factors representing the shared variance among those tasks. Table 1 shows the scores and Table 2 displays the intercorrelations for the neuropsychological tests from which factors were derived. We applied an a priori factor structure based on previous work (Miyake et al., 2000; Park et al., 2002; Salthouse et al., 2003, 2011; Friedman and Miyake, 2004; Hedden and Yoon, 2006). To prevent tuning the factor structure to the imaging data, we hypothesized the factor structure in advance, did not allow modifications without strong theoretical justification, and finalized the factor structure on neuropsychological data without links to amyloid or WMH imaging data. We took a strict stance in evaluating our hypothesized model (depicted in Fig. 1), allowing for only one nonhypothesized path from memory to the SOP task, which involves repeated trials and therefore has an episodic memory component. This model fit the data well: $\chi^{2}(79)=85.49, p=0.29$, TLI $=0.986$, RMSEA $=$ 0.022 , PCLOSE $=0.95$. The original model excluding the path from memory to the SOP task also fit the data well, $\chi^{2}(80)=$ $101.11, p=0.06, \mathrm{TLI}=0.954, \mathrm{RMSEA}=0.040, \mathrm{PCLOSE}=0.76$, but the addition of this path resulted in a significant improvement in model fit, $\Delta \chi^{2}(1)=15.62, p<0.001$. Although we accepted this model for its failure to reject our a priori hypothesis of the specified factor structure, this model was also preferred relative to all tested alternative models (Table 3 ); these alternatives were evaluated solely to confirm that our hypothesized factor structure provided a better fit to our data than do other likely hypothetical factor structures. This model was used to extract factor scores for each participant in the sample; these were carried forward for additional analysis.

To assess how model fit may be affected by our sample characteristics, we estimated the accepted model in two subsamples. The first was a subsample of 143 subjects after randomly removing 25 individuals aged $<70$ years to account for oversampling of individuals in this age range in our sample. The second was the subsample of 109 subjects with both amyloid and WMH imaging data, although it should be noted that fit in this subsample was evaluated without reference to the imaging data. As shown in Table 3, good fit was obtained for both subsamples and the fit within these subsamples was comparable to that in the full sample. No major qualitative differences were observed in the factor loadings or interfactor correlations between these subsample models and the accepted model. These results indicate that the 
Table 1. Demographic and neuropsychological data

\begin{tabular}{|c|c|c|c|c|c|c|}
\hline & Older $(N$ & & Older (OB & & Young $(\Lambda$ & \\
\hline & $M$ & SD & $M$ & SD & $M$ & SD \\
\hline Age & 73.24 & 5.80 & 73.51 & 5.80 & 22.03 & 3.69 \\
\hline Executive function & -0.23 & 0.91 & -0.25 & 0.92 & 1.00 & 0.70 \\
\hline Fluency & -0.18 & 0.97 & -0.20 & 0.95 & 0.79 & 0.74 \\
\hline FAS & 47.23 & 13.97 & 47.79 & 13.99 & 46.76 & 11.10 \\
\hline Categories & 45.44 & 9.75 & 44.83 & 9.16 & 51.37 & 7.69 \\
\hline Working memory & -0.16 & 0.95 & -0.17 & 0.97 & 0.73 & 0.87 \\
\hline LNS & 9.77 & 2.58 & 9.75 & 2.66 & 11.79 & 2.76 \\
\hline BDS & 5.26 & 1.18 & 5.28 & 1.19 & 5.39 & 1.20 \\
\hline SOP* & 3.86 & 1.19 & 3.85 & 1.20 & 2.47 & 0.70 \\
\hline Switching & -0.19 & 0.98 & -0.24 & 0.96 & 0.84 & 0.54 \\
\hline NL switch* & 752 & 462 & 745 & 508 & 292 & 156 \\
\hline Flanker Comp.* & 235 & 254 & 234 & 226 & 60 & 43 \\
\hline TMT B-A* & 48 & 37 & 50 & 37 & 28 & 17 \\
\hline Memory & -0.29 & 0.84 & -0.32 & 0.87 & 1.27 & 0.56 \\
\hline FNAME CRN & 4.85 & 3.64 & 4.72 & 3.76 & 10.58 & 2.98 \\
\hline FNAME CRO & 8.84 & 3.54 & 8.71 & 3.46 & 12.53 & 2.10 \\
\hline SRT DR & 5.58 & 2.81 & 5.44 & 3.02 & 10.00 & 1.96 \\
\hline MCT FR List 2 & 7.43 & 3.11 & 7.39 & 3.08 & 11.53 & 2.58 \\
\hline Speed & -0.28 & 0.81 & -0.27 & 0.84 & 1.22 & 0.83 \\
\hline NL nonswitch* & 1083 & 234 & 1082 & 237 & 735 & 127 \\
\hline TMT A* & 36 & 11 & 36 & 12 & 21 & 6 \\
\hline Digit Symbol & 48.70 & 10.48 & 48.97 & 10.91 & 67.26 & 13.02 \\
\hline
\end{tabular}

FAS, letter fluency; LNS, letter-number sequencing; BDS, backward digit span; SOP, self-ordered pointing; NL, number-letter; Comp., compatibility; TMT, Trail Making Test; FNAME, Face-Name Associative Memory Exam; CRN, cued recall for names; CRO, cued recall for occupations; SRT DR, Selective Reminding Test Delayed Recall; MCT FR, Memory Capacity Test Free Recall. *Variable was reverse-scaled prior to entry in confirmatory factor analysis.

Table 2. Correlations between tasks

\begin{tabular}{|c|c|c|c|c|c|c|c|c|c|c|c|c|c|c|c|c|}
\hline 1. Age & 1 & 2 & 3 & 4 & 5 & 6 & 7 & 8 & 9 & 10 & 11 & 12 & 13 & 14 & 15 & 16 \\
\hline 2. VIQ & 0.04 & & & & & & & & & & & & & & & \\
\hline 3. FAS & 0.01 & 0.51 & & & & & & & & & & & & & & \\
\hline 4. Categories & -0.20 & 0.34 & 0.53 & & & & & & & & & & & & & \\
\hline 5. LNS & -0.13 & 0.27 & 0.27 & 0.37 & & & & & & & & & & & & \\
\hline 6. BDS & -0.03 & 0.39 & 0.35 & 0.30 & 0.37 & & & & & & & & & & & \\
\hline 7. SOP* & -0.36 & 0.24 & 0.18 & 0.21 & 0.25 & 0.18 & & & & & & & & & & \\
\hline 8. NL Switch* & -0.06 & 0.17 & 0.19 & 0.21 & 0.06 & 0.12 & 0.20 & & & & & & & & & \\
\hline 9. Flanker Comp.* & -0.29 & 0.03 & 0.14 & 0.13 & 0.02 & 0.10 & 0.18 & 0.18 & & & & & & & & \\
\hline 10. TMT B-A* & -0.20 & 0.36 & 0.35 & 0.34 & 0.16 & 0.27 & 0.24 & 0.17 & 0.33 & & & & & & & \\
\hline 11. FNAME CRN & -0.23 & 0.18 & 0.09 & 0.21 & 0.10 & 0.11 & 0.32 & 0.13 & 0.04 & 0.18 & & & & & & \\
\hline 12. FNAME CRO & -0.27 & 0.24 & 0.15 & 0.30 & 0.09 & 0.22 & 0.36 & 0.11 & 0.11 & 0.23 & 0.55 & & & & & \\
\hline 13. SRT DR & -0.14 & 0.19 & 0.24 & 0.36 & 0.15 & 0.12 & 0.31 & 0.22 & 0.07 & 0.15 & 0.50 & 0.40 & & & & \\
\hline 14. MCT FR List 2 & -0.22 & 0.25 & 0.31 & 0.34 & 0.24 & 0.17 & 0.32 & 0.18 & 0.04 & 0.23 & 0.47 & 0.48 & 0.53 & & & \\
\hline 15. NL Nonswitch* & -0.24 & 0.12 & 0.23 & 0.35 & 0.22 & 0.19 & 0.27 & 0.19 & 0.40 & 0.25 & 0.22 & 0.27 & 0.18 & 0.25 & & \\
\hline 16. TMT $A^{*}$ & -0.12 & 0.21 & 0.13 & 0.32 & 0.16 & 0.12 & 0.15 & 0.07 & 0.16 & 0.20 & 0.11 & 0.10 & 0.17 & 0.15 & 0.31 & \\
\hline 17. Digit symbol & -0.22 & 0.25 & 0.37 & 0.50 & 0.17 & 0.28 & 0.27 & 0.19 & 0.26 & 0.42 & 0.18 & 0.23 & 0.28 & 0.36 & 0.52 & 0.53 \\
\hline
\end{tabular}

Boundaries indicate within-factor correlations. Values $> \pm 0.13$ are significant at $p<0.05$, one-tailed. $N=168$. Abbreviations are as in Table 1. VIQ, verbal intelligence. ${ }^{*}$ Variable was reverse-scaled.

model fit and resulting factor scores are unlikely to be affected by oversampling of younger subjects or the inclusion of individuals without imaging data types.

\section{Age effects on cognitive performance}

To estimate the cross-sectional age effects on the factor scores across the adult lifespan, we used data collected from a comparison sample of 38 younger adults and computed the factor scores for executive function and its components, memory, and processing speed using the factor weights derived from the sample of 168 older adults. This analytic strategy assumes that the factor structure is the same for younger and older adults; we are unable to test this assumption with confidence given the small sample of younger adults. These younger adults had significantly lower estimated VIQ scores than did the 168 older adults $-t_{(204)}=2.51$, $p=0.01-$ yet outperformed the older adults on all factors, such as, executive function: $t_{(204)}=7.80, p<0.001$; fluency: $t_{(204)}=$ 5.80, $p<0.001$; working memory: $t_{(204)}=5.30, p<0.001$; switching: $t_{(204)}=6.25, p<0.001$; memory: $t_{(204)}=10.89, p<$ 0.001 ; and processing speed: $t_{(204)}=10.20, p<0.001$. These results exemplify the sensitivity of the factor scores for detecting cross-sectional age differences between younger and older adults. Note that because the factor scores were derived from the older adults and applied without additional tuning to the younger adults, methodological influences leading to misfit in out-ofsample data would be expected to work against detecting such cross-sectional age differences.

Within the 168 older adults, cross-sectional age effects were observed on all factors, such as, executive function: $r=-0.26$, $p=0.001$; fluency: $r=-0.22, p=0.004$; working memory: $r=$ $-0.19, p=0.01$; switching: $r=-0.27, p<0.001$; memory: $r=$ $-0.30, p<0.001$; and processing speed: $r=-0.24, p=0.002$. The consistency of the relations to age across domains is primarily due to the selection of domains known to be sensitive to age effects. 


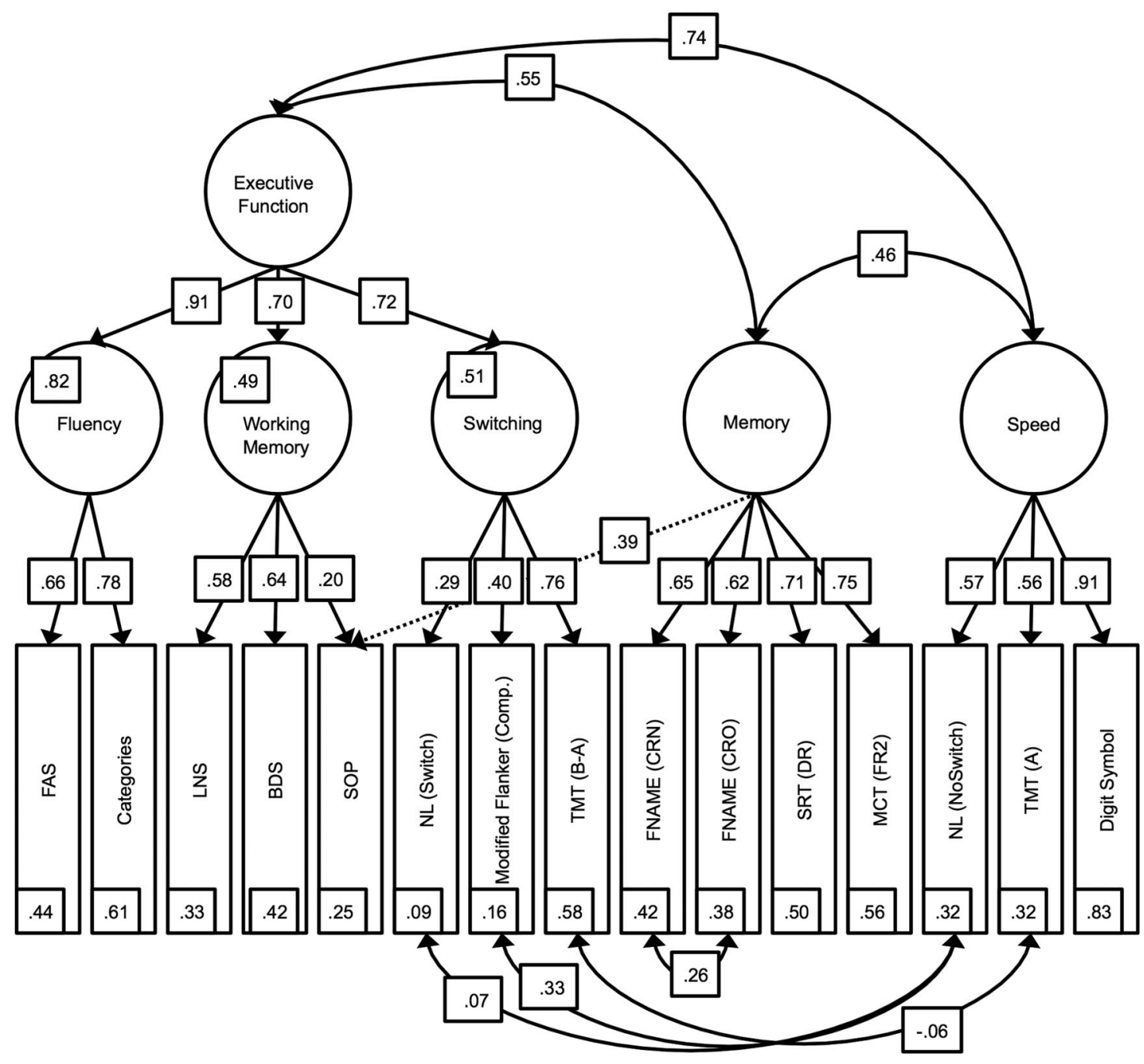

Figure 1. Confirmatory factor analysis of cognitive domains. The model has good fit: $\chi^{2}(79)=85.49, p=0.29, \mathrm{TLI}=0.986, \mathrm{RMSEA}=.022, \mathrm{PCLOSE}=0.95$. Rectangles represent indicators (observed variables), circles indicate latent factors (constructs). Curved arrows indicate correlations between factors (top) or correlated error terms of indicators (bottom). Straight lines indicate path weights. The dotted line indicates the only nonhypothesized path, which was included due to a post hoc theoretical justification and significant impact on model fit. $N=168$.

Table 3. Comparison of confirmatory factor analysis models

\begin{tabular}{lcccccccc}
\hline Model & $\chi^{2}$ & $d f$ & $p$ & TLI & RMSEA & PCLOSE & $\Delta \chi^{2}$ & $\Delta d f$ \\
\hline 1. Hypothesized model: second-order EF factor & 101.11 & 80 & 0.06 & 0.954 & 0.040 & 0.76 & 15.62 & 1 \\
Add memory $\rightarrow$ SOP & 85.49 & 79 & 0.29 & 0.986 & 0.022 & 0.95 & $<0.001$ \\
2. One EF factor & 105.67 & 82 & 0.04 & 0.950 & 0.042 & 0.72 & 20.18 & 3 \\
3. Three EF factors & 79.87 & 75 & 0.33 & 0.989 & 0.020 & 0.95 & -5.62 & 4 \\
4. One factor & 218.54 & 86 & $<0.001$ & 0.730 & 0.096 & $<0.001$ & 133.05 & 7 \\
6. $N=143$ & 84.35 & 79 & 0.32 & 0.986 & 0.022 & 0.93 & $<0.001$ \\
7. $N=109$ & 82.05 & 79 & 0.39 & 0.990 & 0.019 & 0.88 & & \\
\hline
\end{tabular}

Note. The italicized model is the accepted model. For each numbered model, $\Delta \chi^{2}$ indicates the improvement (negative values) or decrement (positive values) in fit relative to the accepted model. A nonsignificant improvement indicates that the improvement in $\chi^{2}$ is not justified by the loss of degrees of freedom ( $d f$ ). Models 2 and 3 included the path from memory to SOP. Model 2 had a unitary executive function (EF) factor, without individual factors for fluency, working memory, and switching. Model 3 had separate EF factors for fluency, working memory, and switching that were correlated but did not include a second-order EF factor. Model 4 had a single factor using all variables as indicators. Models 6 and 7 provide the results for the accepted model using different subsamples. Model 6 indicates the results of the accepted model after random removal of 25 individuals aged $<70$ to account for oversampling of this age range in the current sample. Model 7 indicates the results of the accepted model applied to only the 109 individuals with amyloid and white matter hyperintensities data and represents a best-case fit for the accepted model in this subsample given that fit was evaluated without reference to the imaging markers. Models 6 and 7 cannot be directly quantitatively compared to the accepted model because they indicate the results from different subsamples of the same population, but both have comparable fit statistics to the accepted model. TLI, Tucker-Lewis Index; RMSEA, root mean square error of approximation; PCLOSE, $p$ value for closeness of fit; SOP, self-ordered pointing.

\section{Effects of crystallized intelligence on performance}

In addition to the observed age effects, we examined a proxy of crystallized intelligence (estimated VIQ) as a predictor of cognitive performance among the older adults. Within the 168 older adults, VIQ had a significant positive relationship to all factors, such as, executive function: $r=0.50, p<0.001$; fluency: $r=0.50$, $p<0.001$; working memory: $r=0.50, p<0.001$; switching: $r=$
0.44, $p<0.001$; memory: $r=0.33, p<0.001$; and processing speed: $r=0.32, p<0.001$. VIQ and age were not correlated in this sample, $r=0.04, p=0.65$.

\section{Amyloid burden and WMH}

Within the sample of 109 older adults with both amyloid and WMH data available, amyloid burden (PiB FLR) was $M=1.24$, 


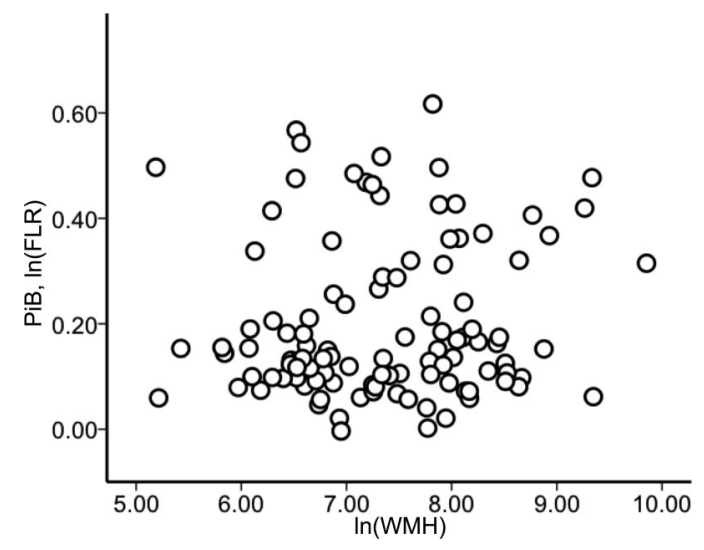

Figure 2. Amyloid burden and WMH are uncorrelated in a sample of cognitively normal older adults. Global measures of amyloid (from the FLR region) and WMH were log-transformed and found to be unrelated to one another whether or not age was controlled ( $r=0.10, p=$ 0.14 ; controlling for age: $r=0.06, p=0.28$ ).

$\mathrm{SD}=0.20$ in DVR units and $M=0.20, \mathrm{SD}=0.15$ in $\ln (\mathrm{DVR})$ units. $\mathrm{WMH}$ values were $M=2407, \mathrm{SD}=2727$ in volumetric units and $M=7.34, \mathrm{SD}=0.94 \mathrm{in} \ln (\mathrm{WMH})$ units. Raw units are presented for descriptive purposes only; log units were used in all analyses because of the non-normal distribution of both amyloid burden and WMH. Age was not significantly related to amyloid burden, $r=0.13, p=0.09$, whereas age was significantly related to $\mathrm{WMH}, r=0.41, p<0.001$.

We examined the relationship between amyloid and WMH and found no significant relationship $(r=0.10, p=0.14$; controlling for age: $r=0.06, p=0.28$; Fig. 2). This corresponds to our previous finding (Hedden et al., 2012) of a nonsignificant relationship between amyloid and WMH in a smaller sample and with independent results (Rutten-Jacobs et al., 2011; Marchant et al., 2012).

\section{Effects of amyloid burden and WMH on cognitive performance}

We examined amyloid burden and WMH for their relationship to cognitive performance by using the factor scores for each of the 109 participants with these imaging data types. Factor scores were extracted from the model of the full sample of 168 older adults (nearly identical results obtained if factor scores are extracted instead only from the 109 participants with full imaging data). These factor scores were entered as observed variables in a path analysis using age, VIQ, amyloid burden, and WMH as predictors. In such models, the effect of each predictor on each outcome variable represents the unique influence of that predictor while simultaneously controlling for all other predictors. Because our previous model indicated that relationships between the executive function components (fluency, working memory, and switching) and other variables operated through the secondorder executive function factor, we entered only this secondorder factor as an outcome variable in the current analysis. Note that among the predictor variables, only age and WMH were modeled as being correlated, as all other correlations could be constrained to zero without impacting model fit.

This analysis is depicted in Figure 3 and produced a well fitting model, $\chi^{2}(5)=6.02, p=0.30$, TLI $=0.985$, RMSEA $=0.043$, PCLOSE $=0.45$. (When factor scores from the 109 participants are used, overall model fit was identical, $\chi^{2}(5)=6.02, p=0.30$, and no individual standardized path weight or correlation changed by $>0.03$ ). However, we are less concerned with the full model fit and more so with the relative weightings and significance of individual paths from the four predictors to each factor score. As can be seen in Figure 3 and confirming the above analyses, the paths from VIQ to executive function, memory, and speed were all significant, as were the paths from age to each of the factors. The path from amyloid burden (PiB FLR) to memory was significant, $p=0.01$, but the paths from amyloid burden to executive function and to speed were not significant $(p=0.50$ and $p=0.36$, respectively). These latter two paths can be constrained to equal zero without impacting model fit, $\Delta \chi^{2}(2)=0.47, p=$ 0.79 . Further, the paths from amyloid burden to memory and from age to memory have equivalent weightings, as they can be fixed to be equal without impacting model fit, $\Delta \chi^{2}(1)=0.98, p=$ 0.75 , suggesting that the influence of amyloid on memory performance is of similar size to that of age on memory.

The paths from WMH to the cognitive factor scores display a distinctly different pattern. The path from WMH to executive function was significant, $p=0.04$. Further, the influence of $\mathrm{WMH}$ on executive function and of age on executive function are of approximately the same magnitude, as these paths can be fixed to be equal without impacting model fit, $\Delta \chi^{2}(1)=0.13, p=0.72$. In contrast, the paths from WMH to memory $(p=0.08)$ and to speed $(p=0.13)$ did not reach significance and constraining these paths to equal zero did not impact model fit, $\Delta \chi^{2}(2)=0.47$, $p=0.79$. Nonetheless, we cannot unreservedly conclude that WMH have no influence on memory and speed, as constraining the paths from WMH to executive functioning, to memory, and to speed to all be equivalent also did not impact model fit $\Delta \chi^{2}(2)=0.77, p=0.68$.

The influences of amyloid and WMH on each cognitive variable are illustrated in Figure 4, which shows the scatter plot of each cognitive factor score after regressing out age and VIQ as a function of amyloid burden or WMH. These results are similar to those from the preceding path analysis except that the simultaneous influences of amyloid and WMH are not explicitly modeled. As can be seen (Fig. 4, left), the effect of amyloid is selective to memory $(r=-0.21, p=0.01)$, with minimal impact on either executive function $(r=0.00, p=$ $0.50)$ or speed $(r=-0.04, p=0.34)$. On the right side, it is apparent that although only the relationship between $\mathrm{WMH}$ and executive function is significant $(r=-0.17, p=0.04)$, this relationship is approximately the same as that with memory $(r=-0.14, p=0.08)$ and speed $(r=-0.11, p=0.13)$. These figures demonstrate that although significant relationships between amyloid, WMH, and cognition can be observed in cross-sectional data on cognitively normal older adults, the effect sizes are small and there remains substantial unexplained variance in cognitive performance among this sample.

We note that the selected model depicted in Figure 3 cannot be distinguished statistically from a model replacing the covariance among factors with a higher order factor (general function; Gf) that explains the shared variance in the executive function, memory, and speed factors. Using such a model, amyloid did not have a significant path to $\mathrm{Gf}(p=0.45)$, and did have a significant path to memory $(p=0.001)$. In contrast, $\mathrm{WMH}$ had a significant relationship to Gf $(p=0.04)$, but did not have a significant relationship to executive function, memory, or speed after controlling for the relationship to Gf. These results conform with the above and suggest that amyloid burden has a specific association with memory performance, whereas the effects of WMHs on cognition are likely more general in nature. 


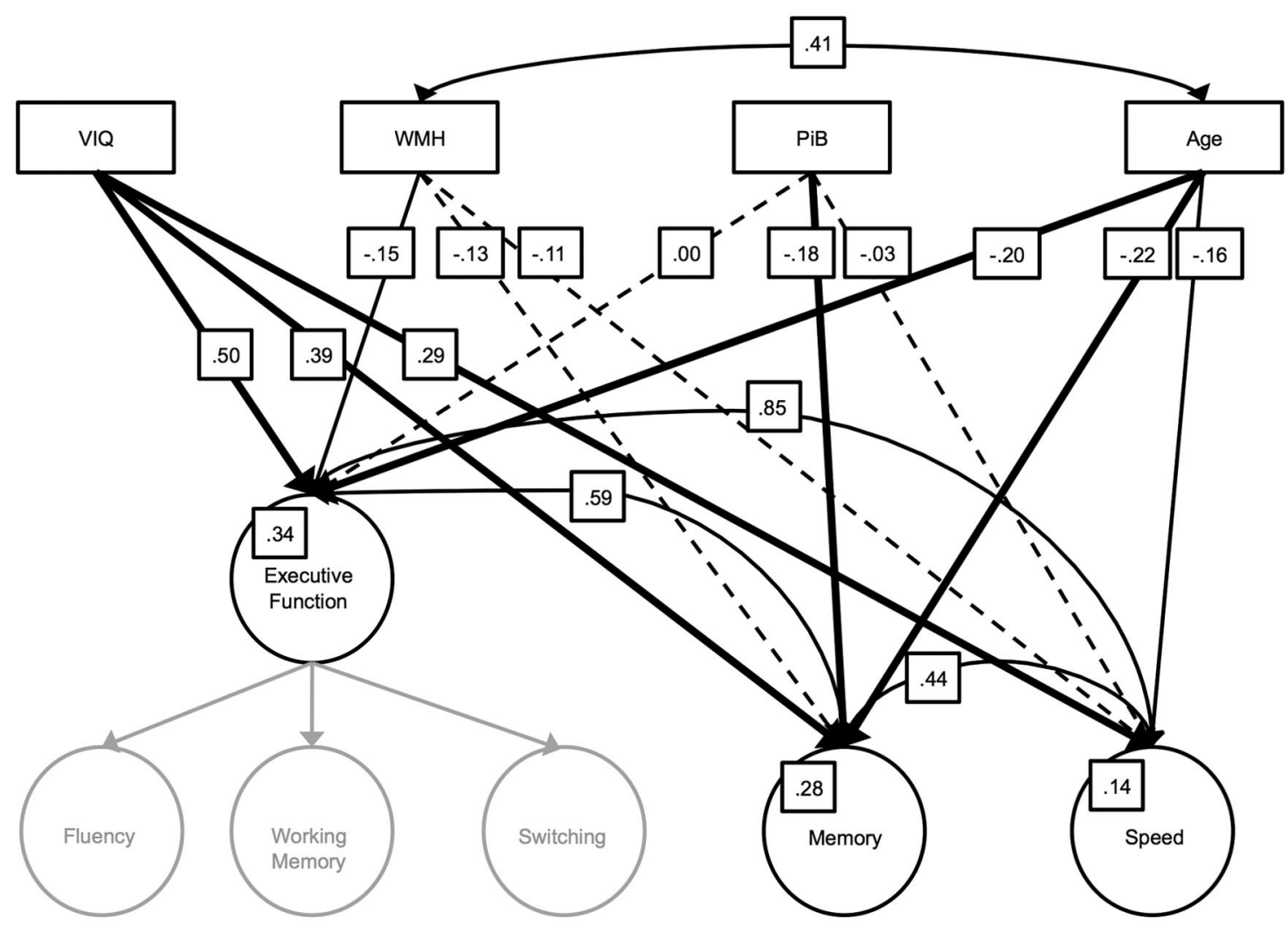

Figure 3. Impact of age, estimated VIQ, PiB, and WMH on cognitive factors. The observed variables of age, VIQ, PiB, and WMH were used to predict individual differences in each cognitive factor. Factor scores were computed from the full model of 168 subjects and entered as observed variables in the model for those 109 subjects with both PiB and WMH data available. The model produced good fit: $\chi^{2}(5)=6.02, p=0.30, \mathrm{TLI}=0.985, \mathrm{RMSEA}=0.043, \mathrm{PCLOSE}=0.45$. The curved arrow at top indicates the only significant correlation among the predictor variables. Straight lines indicate path weights. Solid bolded lines indicate paths significant at $p<0.025$ one-tailed. Solid nonbolded lines indicate paths significant at $p<0.05$ one-tailed. Dashed lines indicate nonsignificant paths. Grayed out factors are represented only implicitly in the model because they contributed to the computation of the executive function second-order factor score.

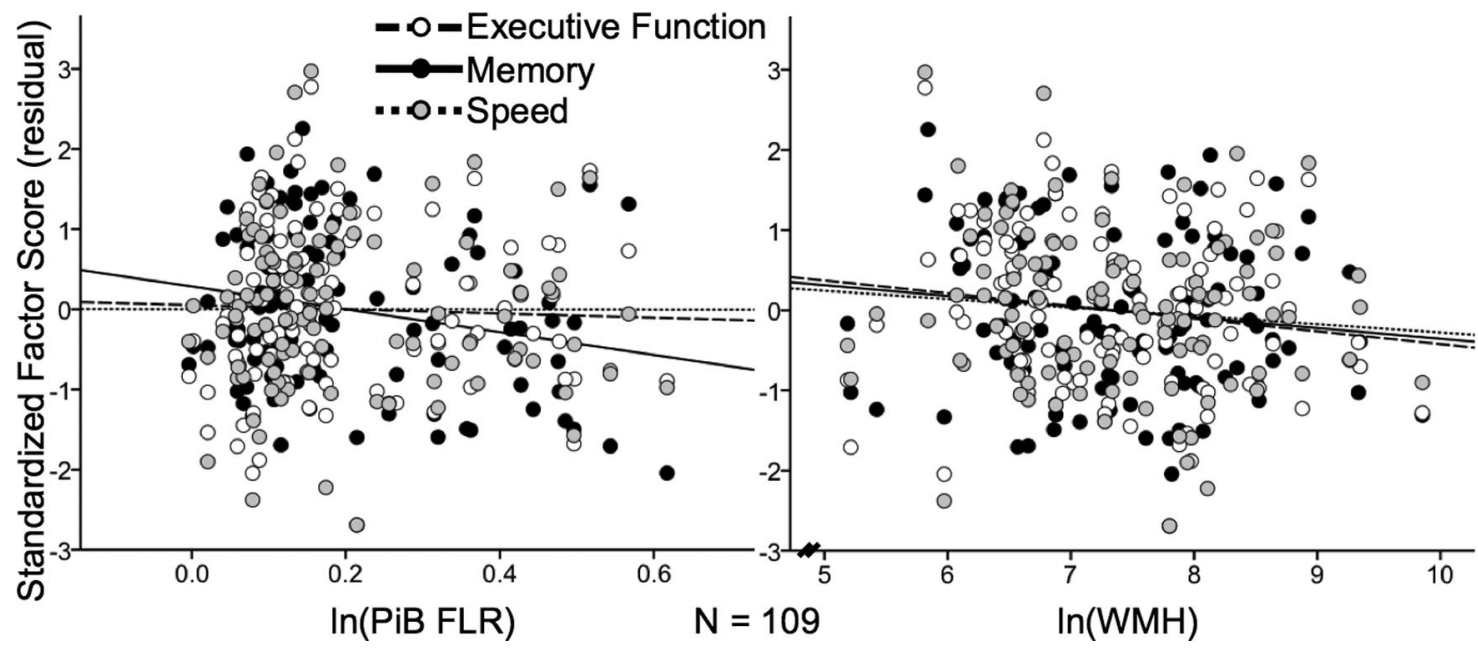

Figure 4. Influence of amyloid burden and WMH on cognition. Left, Amyloid burden (log-transformed PiB DVR) was significantly related to memory ( $r=-0.21, p=0.01)$, with no significant relation to executive function $(r=0.00, p=0.50)$ or speed $(r=-0.04, p=0.34)$. Right, WMH (log-transformed WMH) were significantly related to executive function $(r=-0.17, p=0.04)$, but not to memory $(r=-0.14, p=0.08)$ or speed $(r=-0.11, p=0.13)$, although these relationships did not significantly differ from one another. Standardized factor scores were computed for the 109 subjects with amyloid and WMH data from the model using the full sample of 168 subjects and were residualized on age and estimated verbal intelligence.

Relationship to executive function component factors

In the above analyses, we examined the influence of amyloid and WMH on the second-order factor for executive function under the assumption that these large-scale pathological measures would not selectively affect executive function component processes. We additionally examined the correlations between each marker of neuropathology and the executive function component factor scores controlling for age and VIQ. For amyloid burden, we found no significant relationship with fluency $(r=0.05$, $p=0.31)$, working memory $(r=-0.06, p=0.26)$, or switching $(r=0.03, p=0.38)$. For WMH, we found a significant relationship for switching $(r=-0.29, p=0.001)$, but the association 
with fluency $(r=-0.14, p=0.07)$ and working memory $(r=$ $-0.01, p=0.48)$ did not reach significance. The magnitude of the association between $\mathrm{WMH}$ and switching was approximately twice as large as that between WMH and the second-order executive function factor described above $(r=-0.17)$, while the association between WMH and fluency is of approximately the same size as that effect. This suggests that WMH may have a selective influence on certain component processes of executive function above and beyond the more general effects involving large-scale cognitive functions (Oosterman et al., 2004), but this finding must be interpreted cautiously as it was not predicted.

\section{Discussion}

In a sample of cognitively normal older adults, we found an association between amyloid burden and memory and between WMH and executive function, even after controlling for age and estimated VIQ. The association between amyloid burden and memory appears to be somewhat specific, as no relationship between amyloid and executive function or speed of processing was observed. The influence of WMH on cognition may be more general, however, as paths from WMH to memory and speed of processing did not significantly differ from that of WMH to executive function.

Amyloid burden and $\mathrm{WMH}$ were not significantly associated with one another, suggesting that these may result from separable neuropathological cascades among cognitively normal older adults. This corresponds to recent findings in cognitively normal samples (Rutten-Jacobs et al., 2011; Hedden et al., 2012; Marchant et al., 2012). However, it must be noted that failure to observe a relationship between amyloid and $\mathrm{WMH}$ in samples restricted to cognitively normal older adults may represent selection bias (those suffering from a "double hit" may be more likely to be classified as cognitively impaired) and we therefore cannot rule out the possibility of an association between these pathologies that may become evident at later disease stages (Brun and Englund, 1986; Polvikoski et al., 2010; Horsburgh et al., 2011; Grimmer et al., 2012; Horiuchi et al., 2012).

The impact of amyloid burden on cognition among cognitively normal individuals has become a topic of immense interest since the advent of in vivo amyloid imaging and the ability to measure CSF biomarkers of amyloid (Scheuner et al., 1996; Klunk et al., 2004). Results within cognitively normal adults have been equivocal due to small sample sizes and inconsistent methods, although recent studies with larger sample sizes appear to be converging on memory as an important cognitive factor that is impacted by amyloid (Klunk, 2011). However, not all studies show a selective effect of amyloid burden on memory, also finding significant effects on global cognition and executive function (Bennett et al., 2012; Rodrigue et al., 2012).

The current study adds to this emerging picture, indicating that in a highly selected cross-sectional sample, in vivo imaging of amyloid burden is associated with memory function, but minimally so with executive function or speed of processing. We used multiple measures of each cognitive domain modeled with confirmatory factor analysis so that measurement error associated with individual tasks was minimized. In addition, our measures of memory included tasks that were designed to be more challenging ( $\mathrm{H}$. Buschke, personal communication; Rentz et al., 2010, 2011) than many standard neuropsychological tests of memory. Hence, these measures may be more sensitive to subtle changes in memory function than have been observable in some previous studies.

WMH appear to be associated with a different cognitive profile from amyloid burden in this sample. In particular, $\mathrm{WMH}$ were associated most strongly with executive function. When specific domains of executive function were examined, $\mathrm{WMH}$ were more strongly associated with task switching than with fluency or working memory. However, WMH also had nonsignificant but nontrivial relationships to memory and speed of processing, suggesting that the effects of WMH on cognition may be less specific in nature. These results accord well with previous findings and particularly with the results of two meta-analyses of associations between WMH and cognition (Gunning-Dixon and Raz, 2000; Oosterman et al., 2004). WMH may therefore represent a separate neuropathological cascade from amyloid accumulation and may be associated with cerebrovascular disease (Reed et al., 2007).

We note that the effects of both amyloid on memory and $\mathrm{WMH}$ on executive function were small, each accounting for $<5 \%$ of the variance in cognitive function. However, each had a comparable effect size as that of age on the respective cognitive domains, indicating that this is a nontrivial influence when accounting for age-associated individual differences in cognitive function. The clinical implications of such small effects may be minimal, although it should be remembered that the effects observed here likely represent the earliest stages of neuropathology; as individuals progress toward clinically detectable impairment, effect sizes are likely to increase. The small effect size may, in part, account for the variation in the literature relating amyloid burden to cognition, especially among earlier studies with small samples. It is also possible that apolipoprotein E (APOE) genotype or other genetic factors may influence the relationship between pathology and cognition (Kantarci et al., 2012). It is important to point out that our sample was highly select in terms of education, estimated intelligence, and SES. Given that education and intelligence may provide a buffer against some effects of neurodegeneration on cognition (Van Veluw et al., 2012), our results may not be fully generalizable to the population at large and the effect sizes may differ from those in a less homogeneous sample. Nonetheless, these results indicate that differential relations between amyloid burden and WMH with cognition are likely to be subtle but observable among cognitively normal older adults when using challenging tests with relatively large samples.

The results additionally indicate that the unique contribution of age to all cognitive domains remained significant even after accounting for the influence of both amyloid burden and $\mathrm{WMH}$. Hence, there remains a substantial age-associated influence on cognition that is not explained by these two common markers of neuropathology. The residual relationship between age and cognition may be better explained by other age-related neurobiological changes, such as neurotransmitter depletion, gray matter atrophy, structural changes in white matter tracts, or declines in functional connectivity. It is also possible that these other neurobiological changes mediate the relationships between amyloid, $\mathrm{WMH}$, and cognition, which would be consistent with the small effects identified in our analysis. Gray matter atrophy, for example, may be a more proximate indicator of neural dysfunction in advanced aging and may mediate the small influences of amyloid burden or WMH on cognition (Head et al., 2008; Mormino et al., 2009; He et al., 2012). Simultaneous measurement of multiple markers of age-related neurobiological change will be necessary to fully understand the complex interactions that underlie cognitive decline in advanced aging (Salthouse, 2011).

In sum, these results indicate that within cognitively normal older adults, increased amyloid burden and increased WMH are associated with different cognitive sequelae, adding to the previously reported dissociation of the two biomarkers, which typi- 
cally occur in different individuals within the cognitively normal range (Hedden et al., 2012; Marchant et al., 2012; Rutten-Jacobs et al., 2011). This supports the hypothesis that advanced aging is associated with multiple neuropathological cascades that differentially impact systems related to memory and executive function (Buckner, 2004; Hedden and Gabrieli, 2004; Hedden et al., 2012). That differential cognitive profiles of biomarkers of neuropathology can be observed cross sectionally in a healthy sample indicates that the earliest stages of neuropathological progression may have a small but measurable cognitive impact and provides hope that such profiles could be used for early disease detection and to measure the success of potential interventions. Most directly, the present results imply that distinct intervention strategies may be required to mitigate early decline in memory and executive function given that they may arise from distinct neuropathological cascades.

\section{References}

Amariglio RE, Frishe K, Olson LE, Wadsworth LP, Lorius N, Sperling RA, Rentz DM (2012) Validation of the face name associative memory exam in cognitively normal older individuals. J Clin Exp Neuropsychol 34:580 587. CrossRef Medline

Bennett, DA, Wilson RS, Boyle PA, Buchman AS, Schneider JA (2012) Relation of neuropathology to cognition in persons without cognitive impairment. Ann Neurol. Advance online publication. Retrieval date May 30, 2012. doi:10.1002/ana.23654. CrossRef

Benton AL, Hamsher K, Varney NR, Spreen O (1983) Contributions to neuropsychological assessment: a clinical manual. New York: Oxford UP.

Brickman AM, Muraskin J, Zimmerman ME (2009) Structural neuroimaging in Alzheimer's disease: do white matter hyperintensities matter? Dialogues Clin Neurosci 11:181-190. Medline

Brun A, Englund E (1986) A white matter disorder in dementia of the Alzheimer type: a pathoanatomical study. Ann Neurol 19:253-262. CrossRef Medline

Buckner RL (2004) Memory and executive function in aging and AD: multiple factors that cause decline and reserve factors that compensate. Neuron 44:195-208. CrossRef Medline

Chen YF, Wang H, Chu Y, Huang YC, Su MY (2006) Regional quantification of white matter hyperintensity in normal aging, mild cognitive impairment, and Alzheimer's disease. Dement Geriatr Cogn Disord 22:177-184. CrossRef Medline

Eriksen BA, Eriksen CW (1974) Effects of noise letters upon identification of a target letter in a non- search task. Percept Psychophys 16:143-149. CrossRef

Fagan AM, Mintun MA, Mach RH, Lee SY, Dence CS, Shah AR, LaRossa GN, Spinner ML, Klunk WE, Mathis CA, DeKosky ST, Morris JC, Holtzman DM (2006) Inverse relation between in vivo amyloid imaging load and cerebrospinal fluid Abeta42 in humans. Ann Neurol 59:512-519. CrossRef Medline

Folstein MF, Folstein SE, McHugh PR (1975) “Mini-mental state.” A practical method for grading the cognitive state of patients for the clinician. J Psychiatr Res 12:189-198. CrossRef Medline

Friedman NP, Miyake A (2004) The relations among inhibition and interference control functions: a latent-variable analysis. J Exp Psychol Gen 133:101-135. CrossRef Medline

Gomperts SN, Rentz DM, Moran E, Becker JA, Locascio JJ, Klunk WE, Mathis CA, Elmaleh DR, Shoup T, Fischman AJ, Hyman BT, Growdon JH, Johnson KA (2008) Imaging amyloid deposition in Lewy body diseases. Neurology 71:903-910. CrossRef Medline

Grimmer T, Faust M, Auer F, Alexopoulos P, Förstl H, Henriksen G, Perneczky R, Sorg C, Yousefi BH, Drzezga A, Kurz A (2012) White matter hyperintensities predict amyloid increase in Alzheimer's disease. Neurobiol Aging 33:2766-2773. CrossRef Medline

Gunning-Dixon FM, Raz N (2000) The cognitive correlates of white matter abnormalities in normal aging: a quantitative review. Neuropsychology 14:224-232. CrossRef Medline

Head D, Rodrigue KM, Kennedy KM, Raz N (2008) Neuroanatomical and cognitive mediators of age-related differences in episodic memory. Neuropsychology 22:491-507. CrossRef Medline

He J, Wong VSS, Fletcher E, Maillard P, Lee DY, Iosif AM, Singh B, Martinez
O, Roach AE, Lockhart SN, Beckett L, Mungus D, Farias ST, Carmichael O, DeCarli C (2012) The contributions of MRI-based measures of gray matter, white matter hyperintensity, and white matter integrity to late-life cognition. AJNR Am J Neuroradiol 33:1797-1803.

Hedden T, Gabrieli JD (2004) Insights into the ageing mind: a view from cognitive neuroscience. Nat Rev Neurosci 5:87-96. CrossRef Medline

Hedden T, Yoon C (2006) Individual differences in executive processing predict susceptibility to interference in verbal working memory. Neuropsychology 20:511-528. CrossRef Medline

Hedden T, Van Dijk KR, Becker JA, Mehta A, Sperling RA, Johnson KA, Buckner RL (2009) Disruption of functional connectivity in clinically normal older adults harboring amyloid burden. J Neurosci 29:12686-12694. CrossRef Medline

Hedden T, Van Dijk KR, Shire EH, Sperling RA, Johnson KA, Buckner RL (2012) Failure to modulate attentional control in advanced aging linked to white matter pathology. Cereb Cortex 22:1038-1051. CrossRef Medline

Holland CM, Smith EE, Csapo I, Gurol ME, Brylka DA, Killiany RJ, Blacker D, Albert MS, Guttmann CR, Greenberg SM (2008) Spatial distribution of white-matter hyperintensities in Alzheimer disease, cerebral amyloid angiopathy, and healthy aging. Stroke 39:1127-1133. CrossRef Medline

Hollingshead AB (1957) Two factor index of social position. Mimeo. New Haven, CT: Yale University.

Hommet C, Mondon K, Constans T, Beaufils E, Desmidt T, Camus V, Cottier JP (2011) Review of cerebral microangiopathy and Alzheimer's disease: relation between white matter hyperintensities and microbleeds. Dement Geriatr Cogn Disord 32:367-378. CrossRef Medline

Horiuchi M, Maezawa I, Itoh A, Wakayama K, Jin LW, Itoh T, Decarli C (2012) Amyloid $\beta 1-42$ oligomer inhibits myelin sheet formation in vitro. Neurobiol Aging 33:499-509. CrossRef Medline

Horsburgh K, Reimer MM, Holland P, Chen G, Scullion G, Fowler JH (2011) Axon-glial disruption: the link between vascular disease and Alzheimer's disease? Biochem Soc Trans 39:881-885. CrossRef Medline

Hu L, Bentler PM (1999) Cutoff criteria for fit indexes in covariance structure analysis: conventional criteria versus new alternatives. Struct Equ Modeling 6:1-55. CrossRef

Jack CR Jr, Knopman DS, Weigand SD, Wiste HJ, Vemuri P, Lowe V, Kantarci K, Gunter JL, Senjem ML, Ivnik RJ, Roberts RO, Rocca WA, Boeve BF, Petersen RC (2012) An operational approach to National Institute on Aging-Alzheimer's Association criteria for preclinical Alzheimer disease. Ann Neurol 71:765-775. CrossRef Medline

Johnson KA, Gregas M, Becker JA, Kinnecom C, Salat DH, Moran EK, Smith EE, Rosand J, Rentz DM, Klunk WE, Mathis CA, Price JC, Dekosky ST, Fischman AJ, Greenberg SM (2007) Imaging of amyloid burden and distribution in cerebral amyloid angiopathy. Ann Neurol 62:229-234. CrossRef Medline

Kantarci K, Lowe V, Przybelski SA, Weigand SD, Senjem ML, Ivnik RJ, Preboske GM, Roberts R, Geda YE, Boeve BF, Knopman DS, Petersen RC, Jack CR Jr. (2012) APOE modifies the association between A $\beta$ load and cognition in cognitively normal older adults. Neurology 78:232-240. CrossRef Medline

Klunk WE (2011) Amyloid imaging as a biomarker for cerebral betaamyloidosis and risk prediction for Alzheimer dementia. Neurobiol Aging 32:S20-S36. CrossRef Medline

Klunk WE, Engler H, Nordberg A, Wang Y, Blomqvist G, Holt DP, Bergström M, Savitcheva I, Huang GF, Estrada S, Ausén B, Debnath ML, Barletta J, Price JC, Sandell J, Lopresti BJ, Wall A, Koivisto P, Antoni G, Mathis CA, et al. (2004) Imaging brain amyloid in Alzheimer's disease with Pittsburgh Compound-B. Ann Neurol 55:306-319. CrossRef Medline

Logan J, Fowler JS, Volkow ND, Wolf AP, Dewey SL, Schlyer DJ, MacGregor RR, Hitzemann R, Bendriem B, Gatley SJ (1990) Graphical analysis of reversible radioligand binding from time-activity measurements applied to [N-11C-methyl]-(-)-cocaine PET studies in human subjects. J Cereb Blood Flow Metab 10:740-747. CrossRef Medline

Lopresti BJ, Klunk WE, Mathis CA, Hoge JA, Ziolko SK, Lu X, Meltzer CC Schimmel K, Tsopelas ND, DeKosky ST, Price JC (2005) Simplified quantification of Pittsburgh Compound B amyloid imaging PET studies: a comparative analysis. J Nucl Med 46:1959-1972. Medline

Marchant NL, Reed BR, DeCarli CS, Madison CM, Weiner MW, Chui HC, Jagust WJ (2012) Cerebrovascular disease, beta-amyloid, and cognition in aging. Neurobiol Aging 33:1006.e102-e1036. Medline

Masur DM, Fuld PA, Blau AD, Crystal H, Aronson MK (1990) Predicting 
development of dementia in the elderly with the Selective Reminding Test. J Clin Exp Neuropsychol 12:529-538. CrossRef Medline

Mathis CA, Wang Y, Holt DP, Huang GF, Debnath ML, Klunk WE (2003) Synthesis and evaluation of 11C-labeled 6-substituted 2-arylbenzothiazoles as amyloid imaging agents. J Med Chem 46:2740-2754. CrossRef Medline

Miyake A, Friedman NP, Emerson MJ, Witzki AH, Howerter A, Wager TD (2000) The unity and diversity of executive functions and their contributions to complex "frontal lobe" tasks: a latent variable analysis. Cognit Psychol 41:49-100. CrossRef Medline

Monsch AU, Bondi MW, Butters N, Salmon DP, Katzman R, Thal LJ (1992) Comparisons of verbal fluency tasks in the detection of dementia of the Alzheimer type. Arch Neurol 49:1253-1258. CrossRef Medline

Mormino EC, Kluth JT, Madison CM, Rabinovici GD, Baker SL, Miller BL, Koeppe RA, Mathis CA, Weiner MW, Jagust WJ, the Alzheimer's Disease Neuroimaging Initiative (2009) Episodic memory loss is related to hippocampal-mediated $\beta$-amyloid deposition in elderly subjects. Brain 132:1310-1323. Medline

Morris JC (1993) The Clinical Dementia Rating (CDR): current version and scoring rules. Neurology 43:2412-2414. CrossRef Medline

Oh H, Madison C, Haight TJ, Markley C, Jagust WJ (2012) Effects of age and $\beta$-amyloid on cognitive changes in normal elderly people. Neurobiol Aging 33:2746-2755. CrossRef Medline

Oosterman JM, Sergeant JA, Weinstein HC, Scherder EJ (2004) Timed executive functions and white matter in aging with and without cardiovascular risk factors. Rev Neurosci 15:439-462. Medline

Park DC, Lautenschlager G, Hedden T, Davidson NS, Smith AD, Smith PK (2002) Models of visuospatial and verbal memory across the adult life span. Psychol Aging 17:299-320. CrossRef Medline

Petrides M, Milner B (1982) Deficits on subject-ordered tasks after frontaland temporal-lobe lesions in man. Neuropsychologia 20:249-262. CrossRef Medline

Pike KE, Ellis KA, Villemagne VL, Good N, Chételat G, Ames D, Szoeke C, Laws SM, Verdile G, Martins RN, Masters CL, Rowe CC (2011) Cognition and beta-amyloid in preclinical Alzheimer's disease: data from the AIBL study. Neuropsychologia 49:2384-2390. CrossRef Medline

Polvikoski TM, van Straaten EC, Barkhof F, Sulkava R, Aronen HJ, Niinist ö L, Oinas M, Scheltens P, Erkinjuntti T, Kalaria RN (2010) Frontal lobe white matter hyperintensities and neurofibrillary pathology in the oldest old. Neurology 75:2071-2078. CrossRef Medline

Price JC, Klunk WE, Lopresti BJ, Lu X, Hoge JA, Ziolko SK, Holt DP, Meltzer CC, DeKosky ST, Mathis CA (2005) Kinetic modeling of amyloid binding in humans using PET imaging and Pittsburgh Compound-B. J Cereb Blood Flow Metab 25:1528-1547. CrossRef Medline

Rabinovici GD, Jagust WJ (2009) Amyloid imaging in aging and dementia: testing the amyloid hypothesis in vivo. Behav Neurol 21:117-128. Medline

Reed BR, Mungas DM, Kramer JH, Ellis W, Vinters HV, Zarow C, Jagust WJ, Chui HC (2007) Profiles of neuropsychological impairment in autopsydefined Alzheimer's disease and cerebrovascular disease. Brain 130: 731-739. CrossRef Medline

Reitan RM (1979) Manual for Administration of Neuropsychological Test Batteries for Adults and Children. Tuscon, AZ: Reitan Neuropsychology Laboratory.

Rentz DM, Locascio JJ, Becker JA, Moran EK, Eng E, Buckner RL, Sperling RA, Johnson KA (2010) Cognition, reserve, and amyloid deposition in normal aging. Ann Neurol 67:353-364. CrossRef Medline

Rentz DM, Amariglio RE, Becker JA, Frey M, Olson LE, Frishe K, Carmasin J, Maye JE, Johnson KA, Sperling RA (2011) Face-name associative memory performance is related to amyloid burden in normal elderly. Neuropsychologia 49:2776-2783. CrossRef Medline

Resnick SM, Sojkova J, Zhou Y, An Y, Ye W, Holt DP, Dannals RF, Mathis CA, Klunk WE, Ferrucci L, Kraut MA, Wong DF (2010) Longitudinal cognitive decline is associated with fibrillar amyloid-beta measured by [11C]PiB. Neurology 74:807-815. CrossRef Medline

Ridderinkhof KR, Band GP, Logan GD (1999) A study of adaptive behavior: effects of age and irrelevant information on the ability to inhibit one's actions. Acta Psychologica 101:315-337. CrossRef

Rodrigue KM, Kennedy KM, Devous MD Sr, Rieck JR, Hebrank AC, Diaz-
Arrastia R, Mathews D, Park DC (2012) $\beta$-amyloid burden in healthy aging: Regional distribution and cognitive consequences. Neurology 78 : 387-395. CrossRef Medline

Roe CM, Mintun MA, D’Angelo G, Xiong C, Grant EA, Morris JC (2008) Alzheimer disease and cognitive reserve: variation of education effect with carbon 11-labeled Pittsburgh Compound B uptake. Arch Neurol 65: 1467-1471. CrossRef Medline

Rogers RD, Monsell S (1995) The cost of a predictable switch between simple cognitive tasks. J Exp Psychol Gen 124:207-231. CrossRef

Rutten-Jacobs LC, de Leeuw FE, Geurts-van Bon L, Gordinou de Gouberville MC, Schepens-Franke AN, Dederen PJ, Spliet WG, Wesseling P, Kiliaan AJ (2011) White matter lesions are not related to beta-amyloid deposition in an autopsy-based study. Curr Gerontol Geriatr Res 2011:826-862. Medline

Ryan J, Paolo A (1992) A screening procedure for estimating premorbid intelligence in the elderly. Clin Neuropsychol 6:53-62.

Salthouse TA (2011) Neuroanatomical substrates of age-related cognitive decline. Psychol Bull 137:753-784. CrossRef Medline

Salthouse TA, Atkinson TM, Berish DE (2003) Executive functioning as a potential mediator of age-related cognitive decline in normal adults. J Exp Psychol Gen 132:566-594. CrossRef Medline

Scheuner D, Eckman C, Jensen M, Song X, Citron M, Suzuki N, Bird TD, Hardy J, Hutton M, Kukull W, Larson E, Levy-Lahad E, Viitanen M, Peskind E, Poorkaj P, Schellenberg G, Tanzi R, Wasco W, Lannfelt L, Selkoe D, et al. (1996) Secreted amyloid beta-protein similar to that in the senile plaques of Alzheimer's disease is increased in vivo by the presenilin 1 and 2 and APP mutations linked to familial Alzheimer's disease. Nat Med 2:864-870. CrossRef Medline

Shimamura AP, Jurica PJ (1994) Memory interference effects and aging: findings from a test of frontal lobe function. Neuropsychology 8: 408-412. CrossRef

Smith SM (2002) Fast robust automated brain extraction. Hum Brain Mapp 17:143-155. CrossRef Medline

Sojkova J, Resnick SM (2011) In vivo human amyloid imaging. Curr Alzheimer Res 8:366-372. CrossRef Medline

Sperling RA, Laviolette PS, O’Keefe K, O’Brien J, Rentz DM, Pihlajamaki M, Marshall G, Hyman BT, Selkoe DJ, Hedden T, Buckner RL, Becker JA, Johnson KA (2009) Amyloid deposition is associated with impaired default network function in older persons without dementia. Neuron 63 : 178-188. CrossRef Medline

Storandt M, Head D, Fagan AM, Holtzman DM, Morris JC (2012) Toward a multifactorial model of Alzheimer disease. Neurobiol Aging 33: 2262-2271. CrossRef Medline

Van Veluw SJ, Sawyer EK, Clover L, Cousijn H, De Jager C, Esiri MM, Chance SA (2012) Prefrontal cortex cytoarchitecture in normal aging and Alzheimer's disease: a relationship with IQ. Brain Struct Funct. Advance online publication. Retrieved June 14, 2012. doi: 10.1007/s00429-012-0381-x. CrossRef

Wakana S, Jiang H, Nagae-Poetscher LM, van Zijl PC, Mori S (2004) Fiber tract-based atlas of human white matter anatomy. Radiology 230:77-87. CrossRef Medline

Wechsler D (1981) WAIS-R manual: Wechsler adult intelligence scalerevised. The Psychological Corporation; Harcourt Brace Jovanovich.

Wechsler D (1987) WMS-R Wechsler memory scale-revised manual. San Antonio, TX: The Psychological Corporation; Harcourt Brace Jovanovich.

Wechsler D (1997) WAIS-III, Wechsler adult intelligence scale administration and scoring manual, Ed 3. New York: The Psychological Corporation.

Wu M, Rosano C, Butters M, Whyte E, Nable M, Crooks R, Meltzer CC, Reynolds CF 3rd, Aizenstein HJ (2006) A fully automated method for quantifying and localizing white matter hyperintensities on MR images. Psychiatry Res 148:133-142. CrossRef Medline

Yesavage JA, Brink TL, Rose TL, Lum O, Huang V, Adey M, Leirer VO (1982) Development and validation of a geriatric depression rating scale: a preliminary report. J Psychiatr Res 17:37-49. Medline

Ylikoski A, Erkinjuntti T, Raininko R, Sarna S, Sulkava R, Tilvis R (1995) White matter hyperintensities on MRI in the neurologically nondiseased elderly. Analysis of cohorts of consecutive subjects aged 55 to 85 years living at home. Stroke 26:1171-1177. CrossRef Medline 